\title{
Balance in single-limb stance in healthy subjects - reliability of testing procedure and the effect of short-duration sub-maximal cycling
}

\author{
Eva Ageberg*1,3, David Roberts², Eva Holmström³ and Thomas Fridén²
}

Address: ${ }^{1}$ Department of Rehabilitation, University Hospital, Lund, Sweden, ${ }^{2}$ Department of Orthopedics, University Hospital, Lund, Sweden and ${ }^{3}$ Department of Physical Therapy, Lund University, Lund, Sweden

Email: Eva Ageberg* - eva.ageberg@sjukgym.lu.se; David Roberts - david.roberts@ort.lu.se; Eva Holmström - eva.holmstrom@sjukgym.lu.se; Thomas Fridén - thomas.friden@ort.lu.se

* Corresponding author

Published: 27 June 2003

BMC Musculoskeletal Disorders 2003, 4:14
Received: 07 March 2003

Accepted: 27 June 2003

This article is available from: http://www.biomedcentral.com/I47/-2474/4//4

(c) 2003 Ageberg et al; licensee BioMed Central Ltd. This is an Open Access article: verbatim copying and redistribution of this article are permitted in all media for any purpose, provided this notice is preserved along with the article's original URL.

\begin{abstract}
Background: To assess balance in single-limb stance, center of pressure movements can be registered by stabilometry with force platforms. This can be used for evaluation of injuries to the lower extremities. It is important to ensure that the assessment tools we use in the clinical setting and in research have minimal measurement error. Previous studies have shown that the ability to maintain standing balance is decreased by fatiguing exercise. There is, however, a need for further studies regarding possible effects of general exercise on balance in single-limb stance. The aims of this study were: I) to assess the test-retest reliability of balance variables measured in single-limb stance on a force platform, and 2) to study the effect of exercise on balance in single-limb stance, in healthy subjects.
\end{abstract}

Methods: Forty-two individuals were examined for test-retest reliability, and 24 individuals were tested before (pre-exercise) and after (post-exercise) short-duration, sub-maximal cycling. Amplitude and average speed of center of pressure movements were registered in the frontal and sagittal planes. Mean difference between test and retest with $95 \%$ confidence interval, the intraclass correlation coefficient, and the Bland and Altman graphs with limits of agreement, were used as statistical methods for assessing test-retest reliability. The paired $t$-test was used for comparisons between pre- and post-exercise measurements.

Results: No difference was found between test and retest. The intraclass correlation coefficients ranged from 0.79 to 0.95 in all stabilometric variables except one. The limits of agreement revealed that small changes in an individual's performance cannot be detected. Higher values were found after cycling in three of the eight stabilometric variables.

Conclusions: The absence of systematic variation and the high ICC values, indicate that the test is reliable for distinguishing among groups of subjects. However, relatively large differences in an individual's balance performance would be required to confidently state that a change is real. The higher values found after cycling, indicate compensatory mechanisms intended to maintain balance, or a decreased ability to maintain balance. It is recommended that average speed and DEV 10; the variables showing the best reliability and effects of exercise, be used in future studies. 


\section{Background}

Fatigue is caused by a combination of different physiological mechanisms occurring at both the central and peripheral levels, leading to decreased motor control [1]. It is therefore reasonable to hypothesize that fatiguing exercise will have an effect on postural control. The maintenance and control of posture and balance in a particular position, or during movement, are fundamental for physical activity. The somatosensory, visual and vestibular systems, as well as the muscle activity, contribute to the maintenance of postural control. This is a person's ability to maintain an appropriate relationship between the body segments and between the body and the environment, and to keep the body's center of mass over the base of support when performing a task [2]. To evaluate postural control in stance, center of pressure (CP) movements can be registered by stabilometry with force platforms [3].

Some authors have reported a decrease in ability to maintain balance in bilateral stance [4-6], and single-limb stance [6-8] after fatiguing exercise, and it has been suggested that individuals are therefore at increased risk of injury when fatigued [6-8]. However, others have found no effect of fatiguing exercise on postural control in single-limb stance [9-11]. In the above-mentioned studies, fatigue was induced by exercise of the lower extremities $[6-8,10,11]$, or by general fatigue $[4,5,9]$. Fatigue induced by general exercise, such as cycling, running or walking, better resembles conditions in daily life and physical activities than fatigue induced by exercising the lower extremities isolated in an isokinetic device. Studies of balance in single-limb stance are of importance since movement patterns of postural control are similar during the stance phase, and many injuries to the lower extremities occur during weight-bearing on one leg [12]. The effect of general fatigue on balance in single-limb stance in healthy subjects has, to our knowledge, only been investigated in one study [9]. Therefore, there is a need for further studies regarding possible effects of fatigue induced by general exercise on postural control, measured by balance in single-limb stance.

It is important to ensure that the assessment tools we use in the clinical setting and in research have measurement error small enough (i.e. high reliability) to detect actual changes in what is being measured. The two components of measurement error are systematic bias, e.g., learning or fatigue effects on the test, and random error due to inherent subject or instrument variation [13]. There is a lack of consensus regarding which statistical tests are the most appropriate for use in reliability studies [13]. Several studies have used the intraclass correlation coefficient (ICC) as a statistical method for assessing test-retest reliability on force platforms [14-16]. However, the ICC has disadvantages; e.g., large variation between subjects results in high
ICC values [13], and the ICC provides a value between 0 and 1 ("relative reliability"), which is difficult to interpret clinically. Therefore, it has been recommended that the ICC be complemented by calculations expressing the actual units of measurement ("absolute reliability"), such as the Bland and Altman graphs with limits of agreement (LOA), and the paired t-test or mean difference between test and retest with a 95\% confidence interval (CI), to assess whether there is a statistically significant bias between the tests (systematic change in the mean) [13]. If several reliability statistics are used; i.e., relative reliability, absolute reliability and analysis of systematic change in the mean, this may provide us with sufficient information about the reliability of the assessment tool.

The purposes of the present study were: 1) to assess the test-retest reliability of balance in single-limb stance measured by stabilometry on a force platform as used in previous studies [3,16-19], and 2) to study the effect of short-duration, sub-maximal cycle ergometry, a standardized method of inducing fatigue [20], on balance in single-limb stance in healthy subjects.

\section{Methods \\ Subjects}

Two groups of healthy volunteers (group 1 and group 2), with no history of neurological disease, major orthopedic lesions, vestibular or visual disturbance were included in the study. Group 1: Forty-two subjects (22 men and 20 women) were included in the test-retest reliability part of the study. Their mean age was 24 years (SD 3 years), mean height $176 \mathrm{~cm}$ (SD $8 \mathrm{~cm}$ ), mean weight $69 \mathrm{~kg}$ (SD $10 \mathrm{~kg}$ ), and median activity level 5 (range 2 to 7 ) according to the Tegner activity level scale, equal to heavy work or recreational jogging on uneven ground twice or more per week [21]. Group 2: Twenty-four subjects (11 men and 13 women) were included in the part of the study regarding the effect of general exercise. Their mean age was 24 years (SD 3 years), mean height $176 \mathrm{~cm}(\mathrm{SD} 8 \mathrm{~cm})$, and mean weight $71 \mathrm{~kg}$ (SD $13 \mathrm{~kg}$ ), and median activity level 5 (range 2 to 9) according to the Tegner activity level scale. The physical activity and age distribution of the subjects in this study were chosen in order to match patients with ligament injuries in the knee. The Research Ethics Committee at Lund University approved the study. All subjects gave their written informed consent to participate in the study.

\section{Assessment}

\section{Stabilometry (group I and group 2)}

Balance in single-limb stance was tested by means of a strain gauge force plate $(33 \times 38 \mathrm{~cm})$ with the subject barefoot in a standardized position [3,16-19] (Figure 1). One foot was placed pointing straight forward in relation to reference lines in the frontal and sagittal planes. The other 


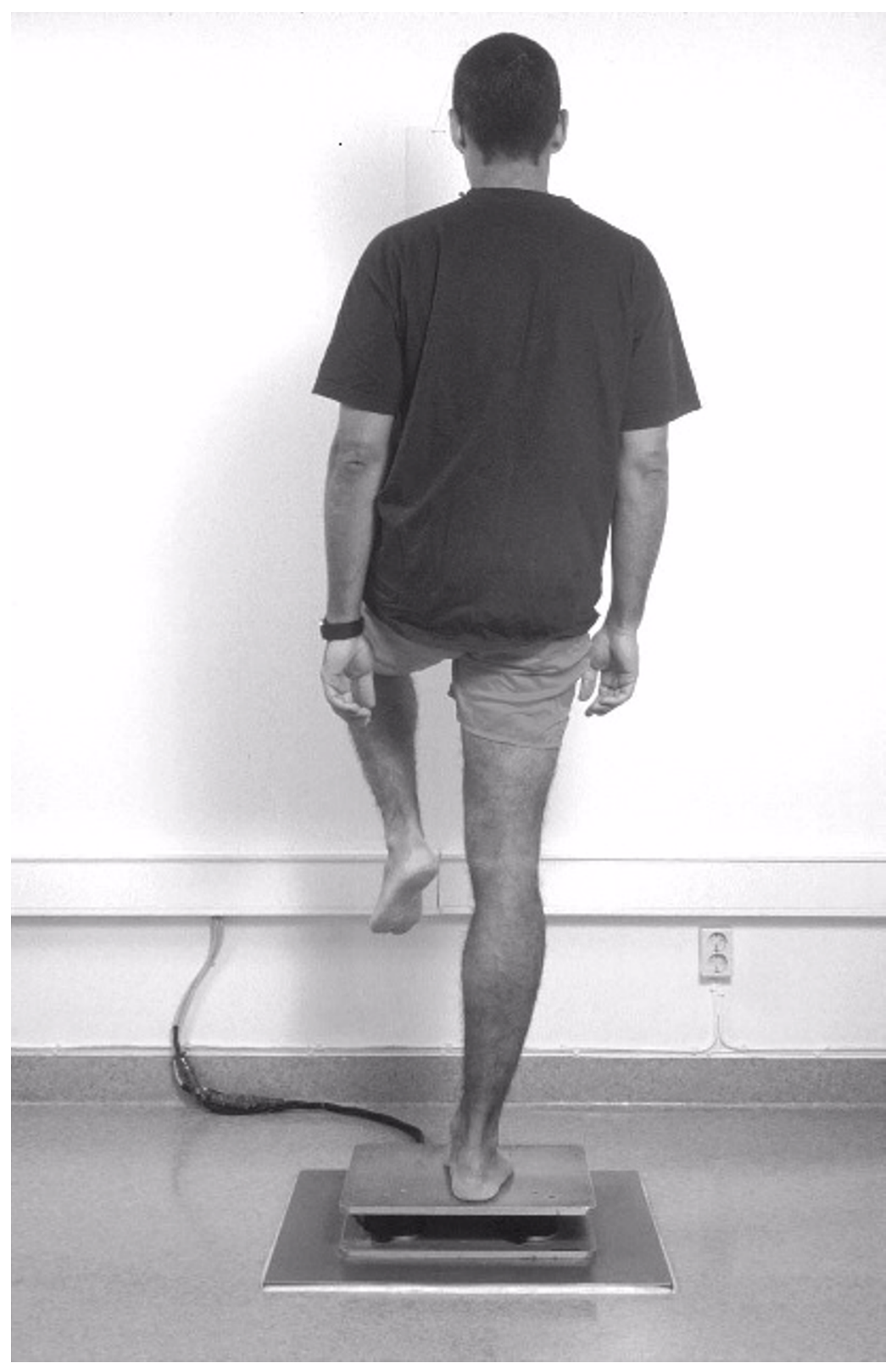

Figure I

Stabilometry in single-limb stance, tested by means of a strain gauge force plate. A standardized position was used. The subject is a model who did not participate in the study. 
leg was flexed $90^{\circ}$ at the hip and knee joints with both arms hanging relaxed at the sides. The subjects were instructed to stand as motionless as possible, looking straight ahead at a point on the wall $65 \mathrm{~cm}$ away; they were allowed to practice maintaining this position for about $20 \mathrm{~s}$ before three measurements were made on each leg, with the subjects standing alternately on their right and left leg. The test order between legs was randomized. Accordingly, the assessment included three measurements taken on the right leg and three on the left leg, giving a total of six measurements on each test occasion. These six measurements lasted for approximately 3.5 minutes. If single-limb balance was not maintained for 25 seconds, the trial was not recorded and the measurement was repeated. However, all subjects in the present study successfully completed the measurements. Movements of the center of pressure (CP) in the frontal plane (FP) and sagittal plane (SP) were recorded for $25 \mathrm{~s}$ at a sampling frequency of $20 \mathrm{~Hz}$. In bilateral stance, a frequency of CP below 1-3 Hz has been found in healthy subjects [22]. A center frequency value of $\mathrm{CP}$ below $2 \mathrm{~Hz}$ has been observed in single-limb stance in the frontal plane in uninjured subjects and in individuals with functional instability of the ankle [23]. We have found no reports on the frequency of $\mathrm{CP}$ in single-limb stance in the sagittal plane. However, according Winter [22] the frequency of $\mathrm{CP}$ is lower in the sagittal plane than in the frontal plane. Thus, it is reasonable to assume that a sampling frequency of $20 \mathrm{~Hz}$ is appropriate for measuring CP movements in single-limb stance. It cannot, however, be excluded that $\mathrm{CP}$ movements at higher frequencies than those that can be recorded at a sampling rate of $20 \mathrm{~Hz}$ may exist. A computer program (Viewdac 2.1, Keithley Instruments, Inc., Cleveland, Ohio, USA), was used to analyze the following variables: 1) standard deviation of the mean value of $C P$ movements in $\mathrm{mm}$, reflecting the amplitude of $\mathrm{CP}$ movements (amplitude);2) average speed of CP movements in $\mathrm{mm} \cdot \mathrm{s}^{-1}$; 3 ) number of movements exceeding $5 \mathrm{~mm}$ from the mean value of $C P$ (DEV 5); and 4) number of movements exceeding $10 \mathrm{~mm}$ from the mean value of $C P$ (DEV 10), giving a total of eight variables (four variables in each plane). The mean value of $\mathrm{CP}$ is the distance $(\mathrm{mm})$ between the $\mathrm{CP}$ and the reference lines, and the amplitude $(\mathrm{mm})$ is its standard deviation. The average speed $\left(\mathrm{mm} \cdot \mathrm{s}^{-1}\right)$ reflects the amplitude and frequency of CP movements, and is calculated as the total length of the path of CP divided by the test trial time. DEV 5 is the number of movements exceeding $5 \mathrm{~mm}$ but less than or equal to $10 \mathrm{~mm}$ from the mean value of $\mathrm{CP}$, and DEV 10 is the number of movements exceeding $10 \mathrm{~mm}$ from the mean value of CP. DEV 5 and DEV 10 reflect the amplitude of CP (i.e., displacement of CP).

The subjects in group 1 were tested twice (test 1 and test 2 ), at about the same time of day with an interval of approximately one week, median value 7 days (range 4-7 days). As previously mentioned, three measurements were made on each leg. The median value of these three measurements was used in the test-retest reliability analyses. The subjects in group 2 were tested before (pre-exercise) and immediately after completion of short-duration, submaximal cycling (post-exercise). The median value of the three measurements and the first and third of the three post-exercise measurements were used in the analyses.

\section{Short-duration sub-maximal exercise (group 2 only)}

Short-duration, sub-maximal exercise was performed on a cycle ergometer. The subjects wore a heart-rate meter during the entire duration of the assessment. Borg's scale for Rating of Perceived Exertion (RPE) [24] was used to assess the subjective effort level during exercise. On this scale, numbers ranging from 6 to 20 are matched with descriptors (e.g., $6=$ No exertion at all, $13=$ Somewhat hard, $15=$ Hard, $17=$ Very hard, $19=$ Extremely hard, and $20=$ Maxi mal exertion). The RPE scale was designed to increase linearly with exercise intensity and heart rate while exercising on a bicycle ergometer, and correlates closely with several physiological variables, including heart rate and blood lactate concentration [24]. A linear relationship exists between heart rate and oxygen consumption with increasing rates of work. A given percentage of maximum oxygen consumption $\left(\mathrm{VO}_{2 \max }\right)$ results in a higher percentage of maximum heart rate $\left(\mathrm{HR}_{\max }\right)$; e.g., $75 \%$ of $\mathrm{VO}_{2 \max }$ represents an intensity of $86 \%$ of the $\mathrm{HR}_{\max }$ [25]. $\mathrm{HR}_{\max }$ can be predicted from the following equation:

Maximum heart rate $($ beats $/ \mathrm{min})=220$ - age $($ years) [25]

Reductions in concentrations of adenosine triphosphate (ATP) and creatine phosphate (CP) in muscle, and large increases in muscle and blood lactate concentrations have been observed after a 4 -min period of exercise on a cycle ergometer above $60 \%$ of $\mathrm{VO}_{2 \max }[20]$.

The rate of pedaling was kept constant at $60 \mathrm{revs} / \mathrm{min}$. The level of exercise was calculated to be similar to that perceived during a general exercise session. Depending on the sex and physical condition of each subject, the workload (W) was set individually aiming at reaching a heart rate above $60 \%$ of the predicted $\mathrm{HR}_{\max }$ in all subjects. The cycling was stopped when the subjects had reached a heart rate exceeding $60 \%$ of the predicted $\mathrm{HR}_{\text {max }}$ perceived the exercise as hard or very hard (values of 14-17 on the RPE scale), and had reached steady-state heart rate; i.e., after approximately $5 \mathrm{~min}$. The exercise on the stationary bicycle took place beside the force platform, so that the test after exercise could be commenced within $10 \mathrm{~s}$.

\section{Statistical analysis}

Since no statistically significant difference was found between the right and left legs in the stabilometric 
variables, the average of the right and left legs; i.e., (right+left)/2, for each stabilometric variable was used for statistical analyses. The use of the mean value of both legs when performing parametric statistics can be questioned, since this may affect the data variability. It cannot, however, be excluded that a dominance of one or the other side exists, which is difficult to define [17], and therefore it is hard to determine which leg to use in comparison with patients. For this reason we used the average of the right and left legs. However, the results were confirmed using the right and left legs separately in the analyses.

\section{Test-retest reliability (group I)}

A number of statistical methods of assessing test-retest reliability were used: 1) mean difference and 95\% confidence interval (CI), 2) the two-way random effect model (absolute agreement definition), average measure ICC and 95\% CI ( ICC $_{2,2}$ according to Shrout \& Fleiss [26]), and 3 ) the Bland and Altman method of assessing agreement, which includes a scatter plot of the differences between test 1 and test 2 against their mean with 95\% limits of agreement (LOA) (i.e., mean difference \pm 2 SD of the difference) [27].

\section{Effects of exercise (group 2)}

The paired t-test was used for the intra-group comparisons. The median value of the three measurements was used to compare pre- and post-exercise values. In addition, the first and third of the post-exercise measurements were compared, to evaluate the instantaneous value of the ability to maintain postural control in single-limb stance (first measurement) and the possible recovery (third measurement).

A level of $\mathrm{P}<0.05$ was chosen to indicate statistical significance. Since the present study has an exploratory character, no correction for multiple comparisons was made. The statistical analyses were performed using the program package SPSS 11.0 (SPSS Inc., Chicago, Ill, USA).

\section{Results \\ Test-retest reliability}

The mean (SD) for test sessions 1 and 2, mean difference with 95\% CI, ICC values, and 95\% LOA between test 1 and test 2 , are given in Table 1. ICC values between 0.79 and 0.95 were found in the stabilometric variables, except for the amplitude in the SP (ICC 0.47). The mean difference and $95 \%$ CI revealed no statistically significant difference between test 1 and test 2 (zero is included in each interval). Figures 2, 3, 4, 5, 6, 7, 8 and 9 show the differences between test sessions 1 and 2 (test 2 minus test 1) plotted against their mean for each subject with 95\% CI and 95\% LOA (see also Table 1). The variables in the FP tended to have smaller mean differences between the test sessions, higher ICC values, and narrower LOAs than the variables in the SP (Table 1).

\section{Effects of exercise}

Short-duration sub-maximal cycling

All subjects exceeded the $60 \%$ value of the predicted $\mathrm{HR}_{\text {max }}$ t the mean value being $81 \%$ (SD 7\%, range 68 to $99 \%$ ). The median power output produced by the subjects at the end of cycling was $150 \mathrm{~W}$ (range 100 to $200 \mathrm{~W}$ ), and the mean value of perceived exertion, rated according to the RPE scale, was 15.4 (SD 0.9). The final heart rate attained was 159 beats/min (SD 14 beats/min), and the heart rate after the stabilometric assessment, approximately 3.5 minutes after the exercise, was 117 beats $/ \mathrm{min}$ (SD 16 beats/min).

\section{Amplitude of CP movements}

No difference was found in the amplitude in the frontal plane (FP) between pre- and post-exercise values. In the sagittal plane (SP) the amplitude was higher post- than pre-exercise $(\mathrm{P}=0.02)$. The mean (SD) for pre- and postexercise values, mean difference with 95\% CI (post-exercise minus pre-exercise), and P-values are given in Table 2. Five $(21 \%)$ subjects had a difference between pre- and post-exercise measurements in the FP outside the LOA, and in the SP, 2 (8\%) subjects had a difference between the measurements outside the LOA. Analysis of the first and third of the post-exercise measurements showed no difference in the FP or SP (Table 3).

\section{Average speed of CP movements}

Higher values were observed post- than pre-exercise in average speed in the FP $(P=0.01)$, although not in the SP (Table 2). One (4\%) subject and 3 (12.5\%) subjects had a difference between pre- and post-exercise measurements outside the LOA in the FP and SP, respectively. No difference was observed between the first and third of the postexercise measurements in the FP or SP (Table 3).

Number of movements exceeding $5 \mathrm{~mm}$ from the mean value of $C P$ No difference was noted between pre- and post-exercise values in DEV 5 in the FP or SP (Table 2). One (4\%) subject and $2(8 \%)$ subjects had a difference between pre- and post-exercise measurements outside the LOA in the FP and SP, respectively. No difference was observed between the first and third of the post-exercise measurements in the FP or SP (Table 3).

Number of movements exceeding $10 \mathrm{~mm}$ from the mean value of $C P$ Higher values were found in DEV 10 post- than pre-exercise in the FP ( $\mathrm{p}=0.03)$, however, not in the SP (Table 2). One $(4 \%)$ subject had a difference between pre- and postexercise measurements in the FP outside the LOA. In the $\mathrm{SP}$, none of the subjects had a difference between the 


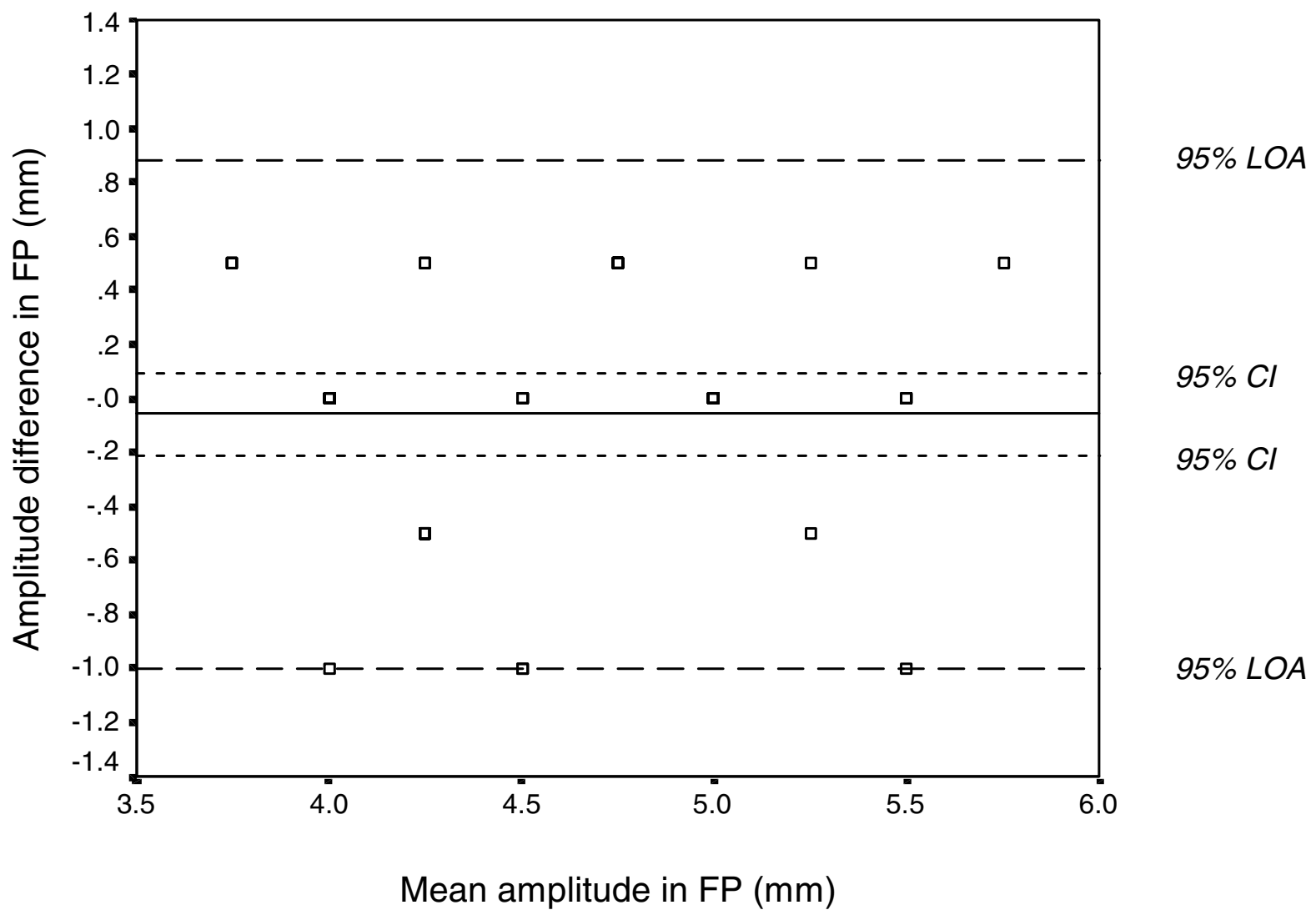

Note: Several subjects have the same value.

\section{Figure 2}

Bland and Altman graph with limits of agreement (LOA). The differences between test sessions I and 2 (test 2 minus test I) plotted against their mean for each subject for the amplitude in $\mathrm{mm}$ in the frontal plane (FP) in 42 healthy subjects, together with the $95 \%$ confidence interval $(\mathrm{Cl})$ and the $95 \%$ LOA.

measurements outside the LOA. No difference was observed between the first and third of the post-exercise measurements in the FP or SP (Table 3).

\section{Discussion}

We have previously reported high reproducibility in healthy subjects for the platform described [16]. However, in that study only the ICC, which is difficult to interpret clinically, was used to assess test-retest reliability. In addition, a systematic error was observed after previous stud- ies, and the platform has therefore been calibrated. For these reasons, a new, extended test-retest reliability study was conducted.

According to the recommendations of Fleiss [28], ICC values above 0.75 represent excellent reliability, while values between 0.4 and 0.75 represent good reliability. All variables, except the amplitude in the SP, showed ICC values above 0.75 , which is in accordance with our previous study [16] and those of others [14,15]. Visual analysis of 


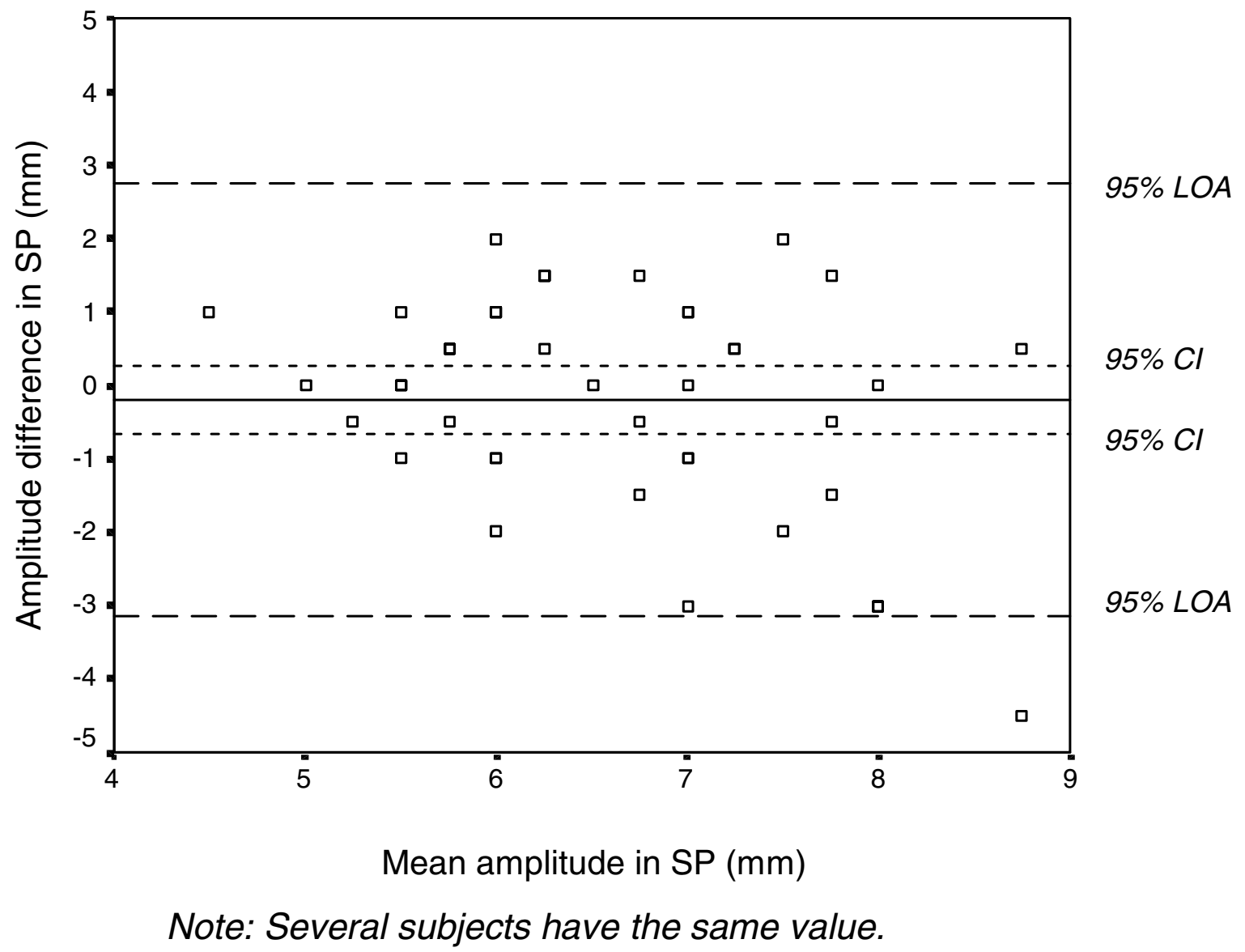

\section{Figure 3}

Bland and Altman graph with limits of agreement (LOA). The differences between test sessions I and 2 (test 2 minus test I) plotted against their mean for each subject for the amplitude in $\mathrm{mm}$ in the sagittal plane (SP) in 42 healthy subjects, together with the $95 \%$ confidence interval $(\mathrm{Cl})$ and the $95 \%$ LOA.

the Bland and Altman graphs and interpretation of the mean difference and 95\% CI between the two test sessions, showed that the values tended to be lower in test session 2, which may be interpreted as a learning process. This tendency was, however, not significant as zero was included in the 95\% CI (Table 1 and Figures 2, 3, 4, 5, 6, 7,8 and 9).

To evaluate changes over time in an individual, the magnitude of the change must exceed the inherent variability of the outcome. The LOA can be used to assess a "real" change in an individual's performance as a result of inter- vention; i.e., if the difference between two measurements is outside the LOA, there is a true change in performance [13]. Since the LOAs were rather wide, the test of balance in single-limb stance we used cannot detect small changes in an individual's performance. In the second part of the study, few subjects $(0-5)$ had a difference between the pre- and post-exercise measurements outside the LOAs, i.e., a "real" change in their individual performance. Most subjects had a difference between the measurements within the LOAs, which does not represent a "real" change in their individual performance. This result confirms that small changes in an individual's performance cannot be 


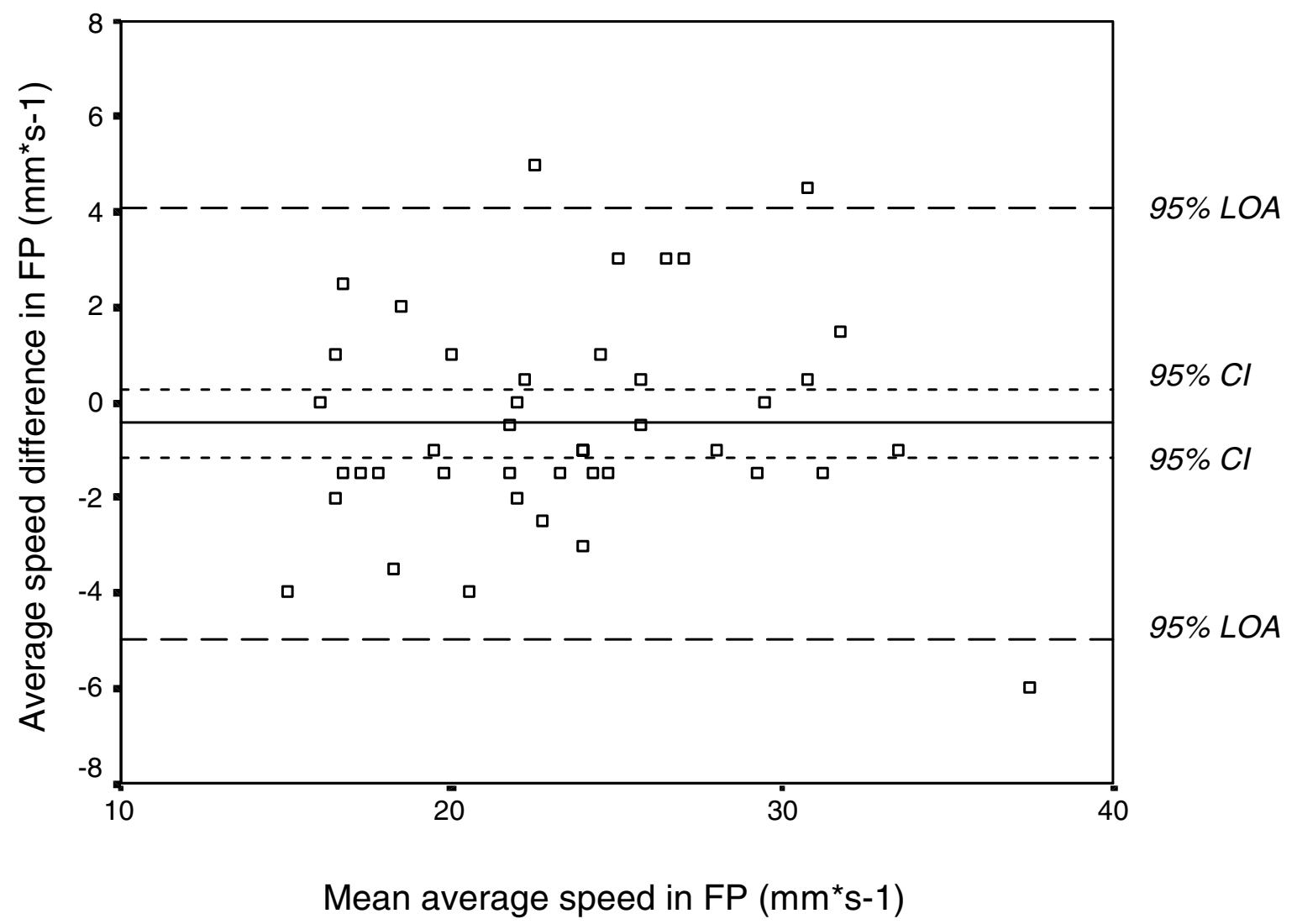

Note: Two subjects have the same value.

\section{Figure 4}

Bland and Altman graph with limits of agreement (LOA). The differences between test sessions I and 2 (test 2 minus test I) plotted against their mean for each subject for the average speed in $\mathrm{mm} \cdot \mathrm{s}^{-1}$ in the frontal plane (FP) in 42 healthy subjects, together with the $95 \%$ confidence interval $(\mathrm{Cl})$ and the $95 \%$ LOA.

detected. Relatively large individual measurement errors for balance in single-limb stance measured on a force platform have also been reported by Birmingham [14]. In that study, SEMs and 95\% CIs were used as measures of absolute reliability, and the results showed that large changes could be detected, but not small changes, in an individual's score [14]. The test of balance in single-limb stance we used may be more useful and appropriate when distinguishing between groups of subjects, such as between patients and controls. To evaluate an individual's change in balance performance, a "true" change would be outside the LOAs. The tendency towards smaller mean dif- ferences between the two test sessions, higher ICC values, and narrower LOAs for the variables in the FP than in the $\mathrm{SP}$, indicates that the variables in the FP may be more reliable.

The second aim of our study was to study the effect of short-duration, sub-maximal general exercise on balance in single-limb stance in healthy subjects. The results revealed higher values post- than pre-exercise in three of the eight measured variables; i.e., the amplitude in the SP, and the average speed and DEV 10 in the FP, whereas the other five variables were unaffected by exercise. In 


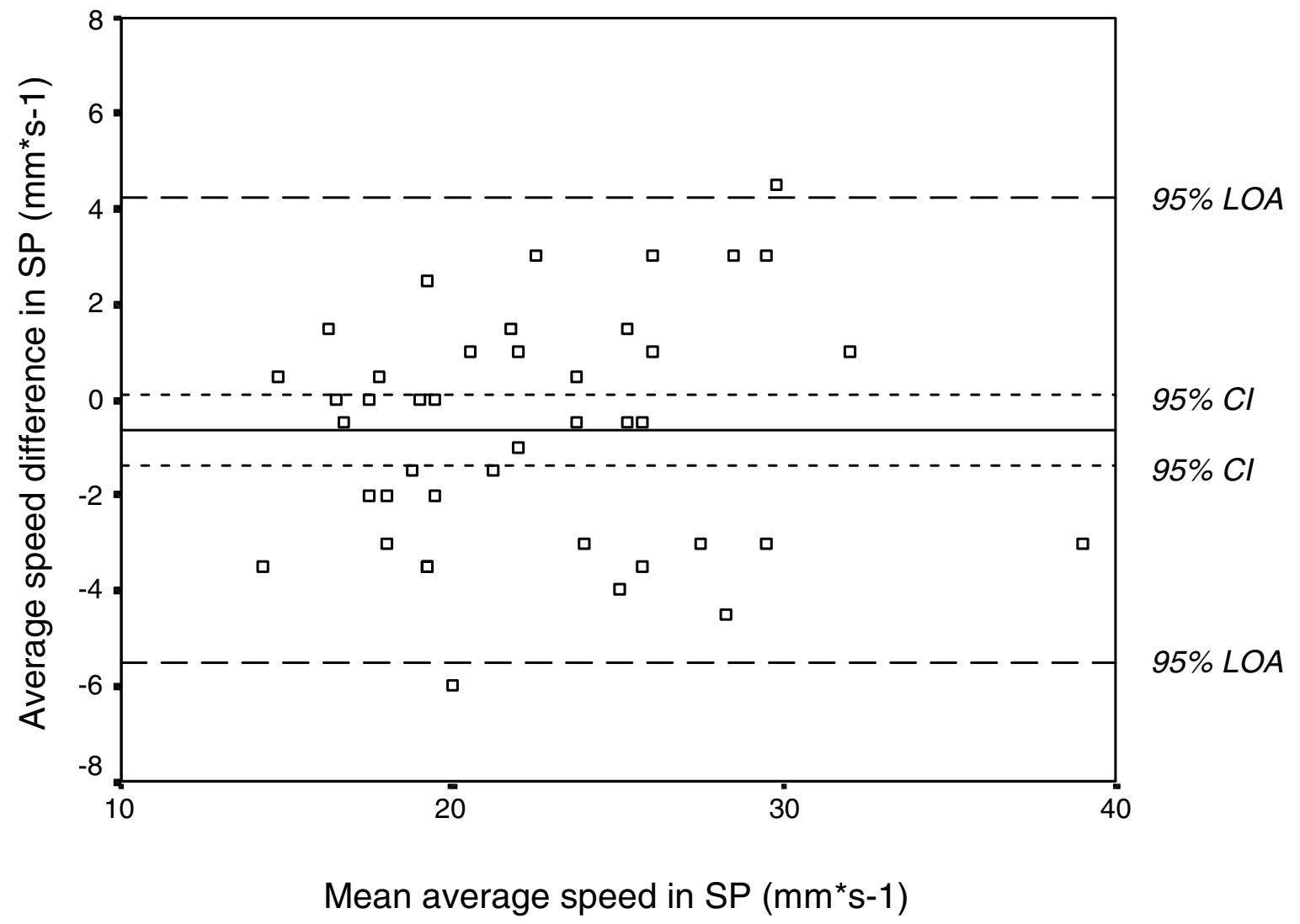

Note: Two subjects have the same value.

\section{Figure 5}

Bland and Altman graph with limits of agreement (LOA). The differences between test sessions I and 2 (test 2 minus test I) plotted against their mean for each subject for the average speed in $\mathrm{mm} \cdot \mathrm{s}^{-1}$ in the sagittal plane (SP) in 42 healthy subjects, together with the $95 \%$ confidence interval $(\mathrm{Cl})$ and the $95 \%$ LOA.

contrast to these higher values found after cycling, all variables tended to have lower values in test session two in the test-retest reliability part of the study. The results of higher values after exercise are supported by the findings of other studies [6-8]. The findings of these studies and our results seem, however, to contradict those of three studies, showing no effect of fatiguing exercise on balance standing on one leg [9-11]. Adlerton \& Moritz [10] used the same force platform as that used in our study. However, their fatiguing protocol was different from ours; a local fatiguing protocol involving requesting the subjects to rise on tiptoe repeatedly, which may explain the diver- gent results. Rozzi et al. [11] suggested that the platform they used had sensitivity too low to detect the effects of muscular fatigue. In the third study mentioned [9], the extent or level of fatigue was not described, which makes it difficult to compare the results with those of other studies.

To evaluate the possible recovery period, the first and third of the post-exercise measurements were compared. It was assumed that the first measurement could provide us with the instantaneous value of the ability to maintain postural control in single-limb stance. No difference was 


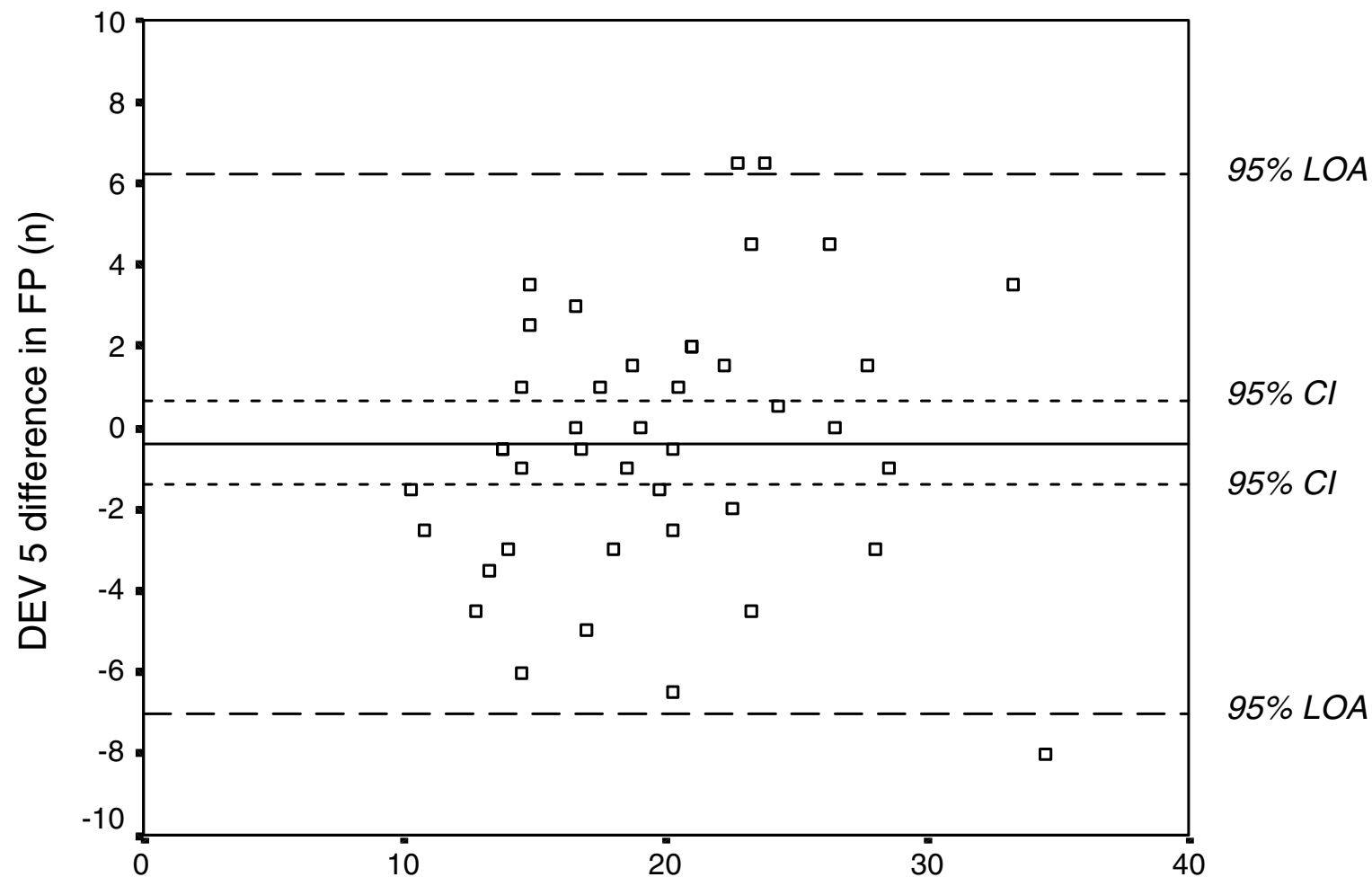

Mean DEV 5 in FP (n)

Note: Several subjects have the same value.

\section{Figure 6}

Bland and Altman graph with limits of agreement (LOA). The differences between test sessions I and 2 (test 2 minus test I) plotted against their mean for each subject for the number of movements exceeding $5 \mathrm{~mm}$ (DEV 5 ) in the frontal plane (FP) in 42 healthy subjects, together with the $95 \%$ confidence interval $(\mathrm{Cl})$ and the $95 \% \mathrm{LOA}$.

found between the first and third of the measurements, which indicates that the initial ability to maintain balance was not more affected by exercise than the final measurement.

We used general exercise on an ergometer cycle, in order to resemble physical activity, with the aim of fatiguing the subjects to the same extent as that perceived during a general exercise session. All subjects in our study exceeded $60 \%$ of the predicted $\mathrm{HR}_{\max }$ value; the values ranging from $68 \%$ to $99 \%$. Since a given percentage of $\mathrm{VO}_{2 \max }$ results in a higher percentage of $\mathrm{HR}_{\max }[25]$, and since the mean value of the predicted $\mathrm{HR}_{\max }$ was $81 \%$, it may be assumed that the subjects had reached a value above $60 \%$ of the predicted $\mathrm{VO}_{2 \text { max }}$; the level above which effects of fatigue have been observed after cycling for a period of four minutes [20]. A short recovery time could be assumed in people with good physical condition, and to avoid recovery, the exercise on the stationary bicycle therefore took place beside the force platform, so that the test after exercise could be commenced within $10 \mathrm{~s}$. Walking or running on a treadmill could not take place beside the force platform, and was therefore impractical. In addition, we plan to study the effect of general exercise in individuals with 


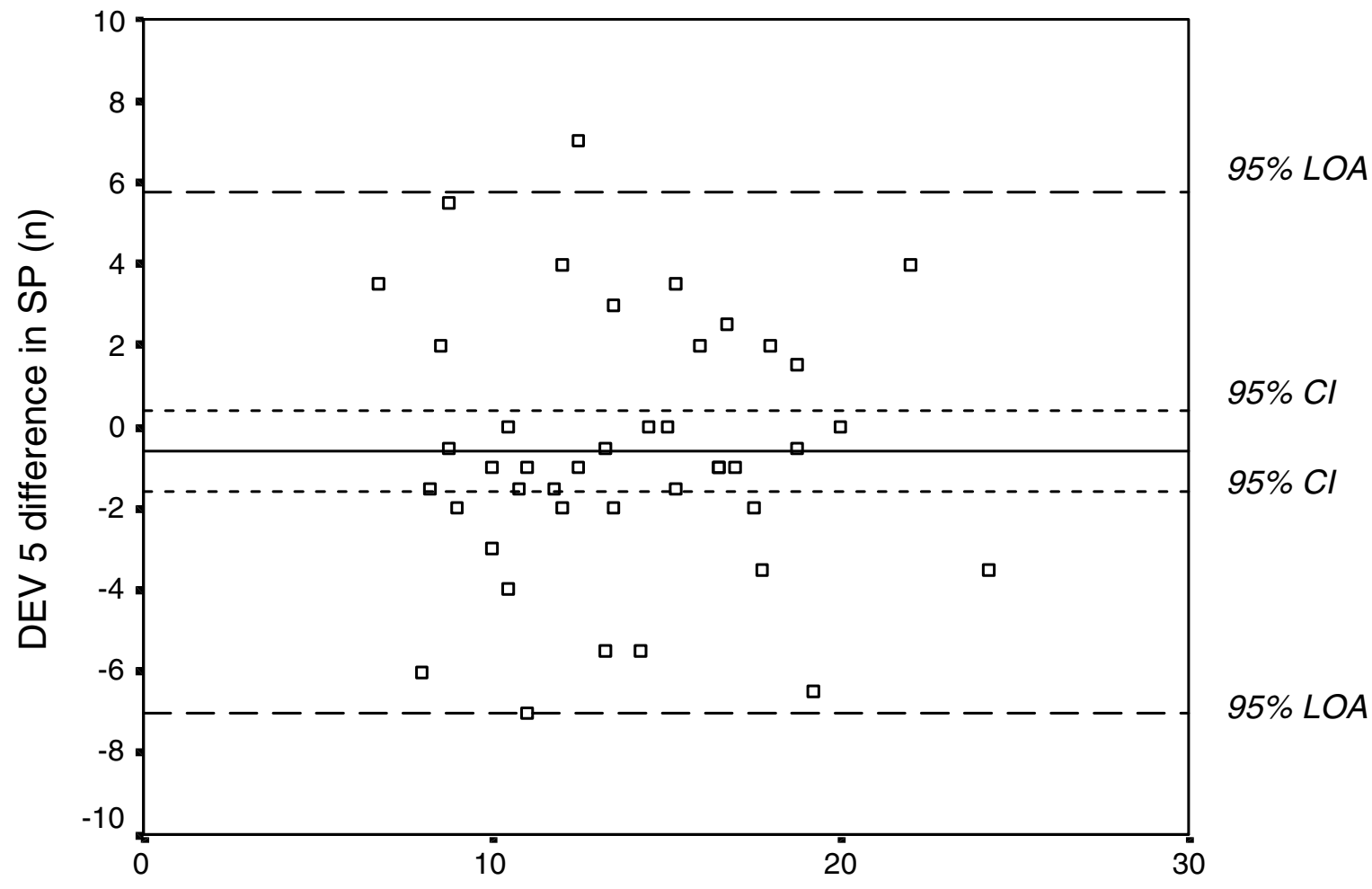

Mean DEV 5 in SP (n)

Note: Two subjects have the same value.

\section{Figure 7}

Bland and Altman graph with limits of agreement (LOA). The differences between test sessions I and 2 (test 2 minus test I) plotted against their mean for each subject for the number of movements exceeding 5 mm (DEV 5) in the sagittal plane $(\mathrm{SP})$ in 42 healthy subjects, together with the $95 \%$ confidence interval $(\mathrm{Cl})$ and the $95 \% \mathrm{LOA}$.

knee injuries at different times after injury, and since the knee is loaded considerably more while running/walking than cycling, cycling was selected due to ethical reasons. We found that short-term, sub-maximal cycling had an effect on balance in single-limb stance. It is, however, possible that larger effects may be seen after running or walking than after cycling. This has been reported in studies assessing postural control while standing on both feet $[4,5]$, indicating that increased loading on the lower extremities affects standing balance to a greater extent. Different methods of inducing fatigue by loading the lower extremities, as well as the effect of general exercise on balancing on one leg after longer durations of exercise than in the present study, need to be further investigated.

To our knowledge, no data is available as to which variables provide the best measure of postural control in single-limb stance. In a previous study on healthy subjects, we reported differences due to age in average speed in the FP and between men and women in both the FP and SP [17]. Amplitude and DEV 10 have been found to be higher among patients with anterior cruciate ligament (ACL) injury compared to a control group of healthy subjects [18]. In that study, CP movements in the FP only 


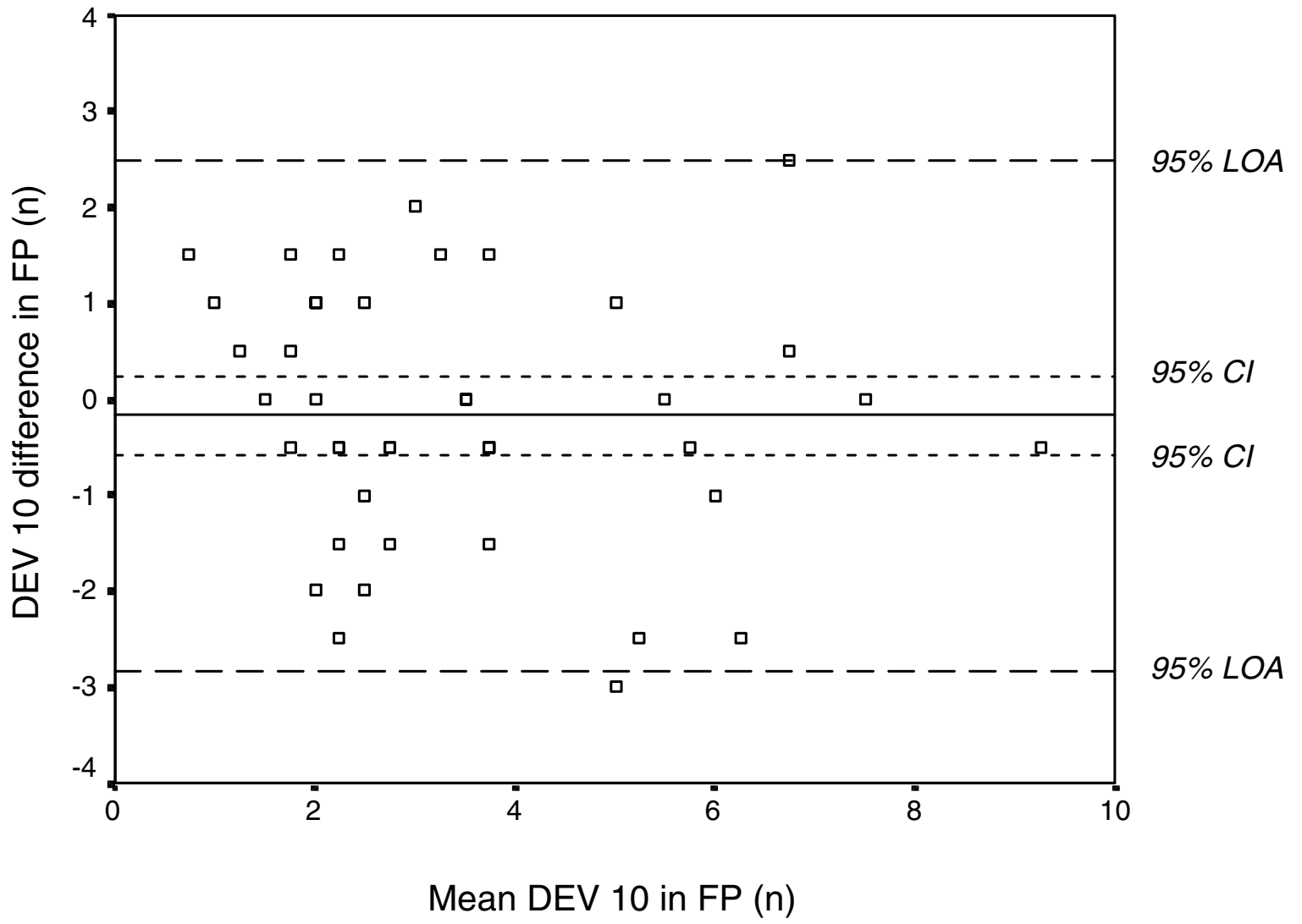

Note: Several subjects have the same value.

\section{Figure 8}

Bland and Altman graph with limits of agreement (LOA). The differences between test sessions I and 2 (test 2 minus test I) plotted against their mean for each subject for the number of movements exceeding $10 \mathrm{~mm}$ (DEV I0) in the frontal plane (FP) in 42 healthy subjects, together with the $95 \%$ confidence interval $(\mathrm{Cl})$ and the $95 \% \mathrm{LOA}$.

were recorded [18]. In the present study, effects of exercise were observed for two variables in the FP (average speed and DEV 10) and one (amplitude) in the SP. Although the amplitude in the SP was able to detect hypothesized changes after the exercise, we recommend that the amplitude variable not be used in future studies, since DEV 10 and amplitude both measure the amplitude of $\mathrm{CP}$ movements, and since the amplitude had poorer reliability in the SP than DEV 10 and was unaffected by exercise in the FP. DEV 5 did not add any information in the present study or in a previous one [18], and can therefore also be excluded in future studies. The results of our pre- vious studies and the present one indicate that measurements in the FP may be more sensitive and revealing than those in the SP. Furthermore, measurements in the FP may be more useful since it is more difficult to maintain the center of mass within the narrow width of the base of support in this plane [29] than in the SP.

The changes in balance in single-limb stance found after exercise in the present study may be explained by several factors. Motor control encompasses the control of posture, balance, and movement. It is dependent on afferent information from muscle spindles, receptors located in 


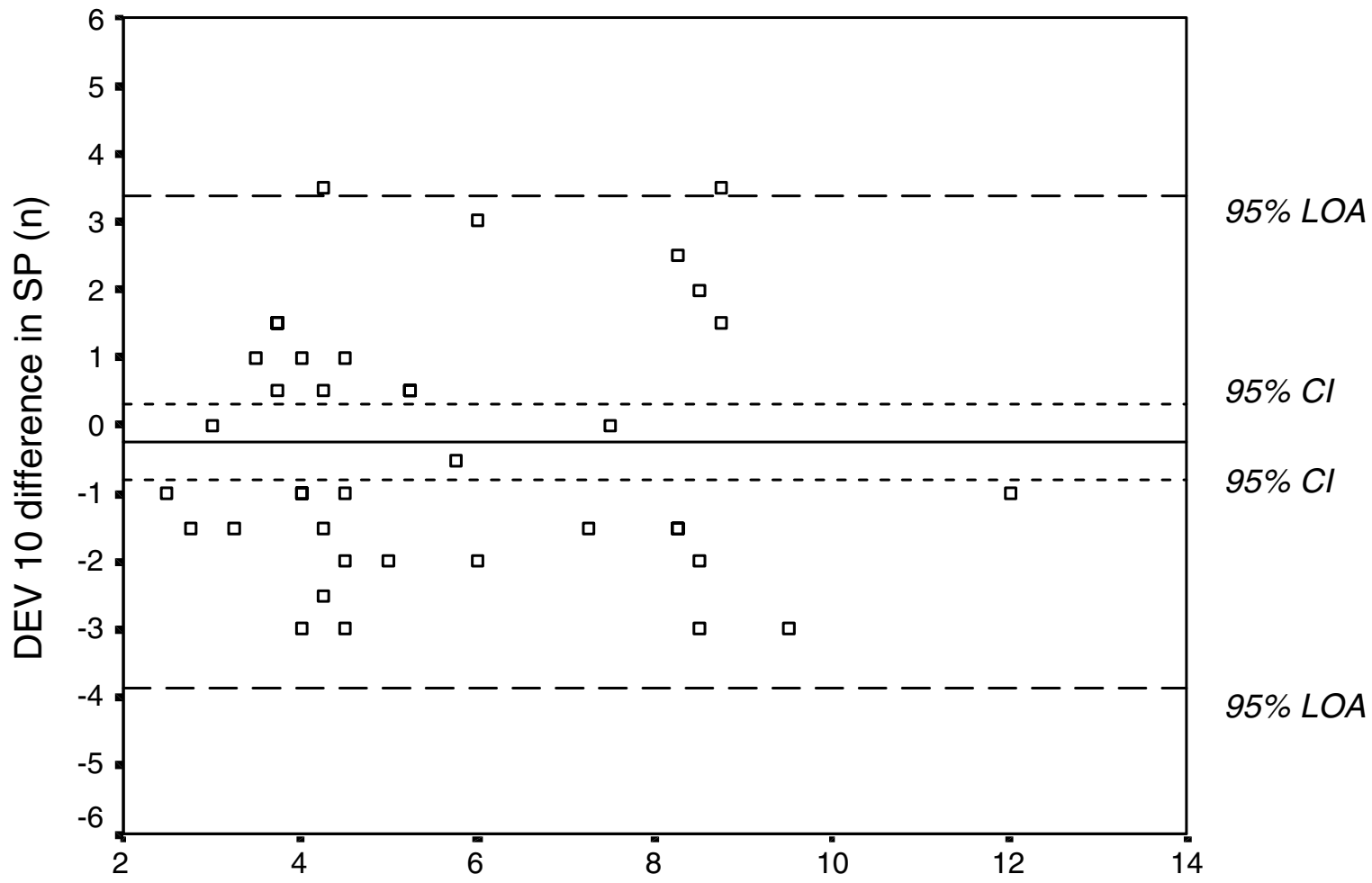

Mean DEV 10 in SP (n)

Note: Several subjects have the same value.

\section{Figure 9}

Bland and Altman graph with limits of agreement (LOA). The differences between test sessions I and 2 (test 2 minus test I) plotted against their mean for each subject for the number of movements exceeding $10 \mathrm{~mm}$ (DEV I0) in the sagittal plane (SP) in 42 healthy subjects, together with the $95 \%$ confidence interval $(\mathrm{Cl})$ and the $95 \% \mathrm{LOA}$.

joint structures, muscles, tendons, and skin, visual and vestibular information, as well as voluntary and reflexive muscular response [30]. The activity of joint receptors, muscle spindles and Golgi tendon organs may be reduced by fatigue, resulting in proprioceptive deficit in muscle receptors and loss of muscular reflexes responsible for dynamic joint stability [31]. Since this afferent information is also important for the maintenance of postural control [30], the decreased muscle response may lead to a poorer ability to maintain balance. Besides the effects of fatigue on standing balance, some studies have also reported increased knee joint laxity $[9,32,33]$, decreased knee proprioception [11,34], and a delay in muscle response [33] following fatiguing exercise. The increased amplitude of CP movements observed after cycling in the present study may be explained by a decrease in muscle response and a delay in muscle reaction, and this larger sway may also explain the increased average speed. These increased values in stabilometry following exercise indicate compensatory mechanisms intended to maintain balance in single-limb stance, or a decreased ability to maintain balance. 
Table I: Test-retest reliability in the stabilometric variables, in $\mathbf{4 2}$ healthy subjects.

\begin{tabular}{|c|c|c|c|c|c|}
\hline & Test session I Mean (SD) & Test session 2 Mean (SD) & Mean difference $(95 \% \mathrm{Cl})$ & ICC $(95 \% \mathrm{CI})$ & $95 \%$ LOA \\
\hline \multicolumn{6}{|l|}{ Frontal plane } \\
\hline Amplitude (mm) & $4.57(0.55)$ & $4.51(0.59)$ & $-0.06(-0.21-0.09)$ & $0.79(0.6 \mathrm{I}-0.89)$ & $-1.00-0.88$ \\
\hline Average speed $\left(\mathrm{mm} \cdot \mathrm{s}^{-1}\right)$ & $23.68(5.38)$ & $23.23(5.5 \mathrm{I})$ & $-0.45(-1.16-0.26)$ & $0.95(0.92-0.98)$ & $-4.99-4.09$ \\
\hline DEV $5(n)$ & $19.94(5.71)$ & $19.57(6.16)$ & $-0.37(-1.40-0.67)$ & $0.92(0.84-0.95)$ & $-6.99-6.25$ \\
\hline DEV $10(n)$ & $3.55(2.14)$ & $3.38(1.96)$ & $-0.17(-0.58-0.25)$ & $0.88(0.78-0.94)$ & $-2.83-2.49$ \\
\hline \multicolumn{6}{|l|}{ Sagittal plane } \\
\hline Amplitude (mm) & $6.70(1.44)$ & $6.51(1.02)$ & $-0.19(-0.65-0.27)$ & $0.47(0.0 \mathrm{I}-0.7 \mathrm{I})$ & $-3.13-2.75$ \\
\hline Average speed $\left(\mathrm{mm} \cdot \mathrm{s}^{-1}\right)$ & $22.84(5.25)$ & $22.21(5.47)$ & $-0.63(-1.39-0.13)$ & $0.94(0.89-0.97)$ & $-5.49-4.23$ \\
\hline DEV 5 (n) & $14.10(4.41)$ & $13.49(4.40)$ & $-0.61(-1.60-0.39)$ & $0.85(0.72-0.92)$ & $-7.01-5.79$ \\
\hline DEV $10(n)$ & $5.63(2.44)$ & $5.38(2.39)$ & $-0.25(-0.81-0.31)$ & $0.84(0.70-0.91)$ & $-3.87-3.37$ \\
\hline
\end{tabular}

Mean (SD) for test sessions I and 2, mean difference (95\% confidence interval) (test 2 minus test I), intraclass correlation coefficient (ICC) ( $95 \%$ confidence interval), and 95\% limits of agreement (LOA) between test sessions I and 2 (test 2 minus test I) in the stabilometric variables (amplitude in $\mathrm{mm}$, average speed in $\mathrm{mm} \cdot \mathrm{s}^{-1}$, and number of movements exceeding $5 \mathrm{~mm}$ (DEV 5) and $10 \mathrm{~mm}$ (DEV I0)) in the frontal and sagittal planes.

Table 2: Effects of exercise in the stabilometric variables, in 24 healthy subjects.

\begin{tabular}{|c|c|c|c|c|}
\hline & Pre-exercise Mean (SD) & Post-exercise Mean (SD) & Mean difference $(95 \% \mathrm{Cl})$ & P-value \\
\hline \multicolumn{5}{|l|}{ Frontal plane } \\
\hline Amplitude (mm) & $4.71(0.66)$ & $4.88(0.59)$ & $0.17(-0.88-0.42)$ & 0.19 \\
\hline Average speed $\left(\mathrm{mm} \cdot \mathrm{s}^{-1}\right)$ & $23.19(5.19)$ & $24.42(5.20)$ & $1.23(0.29-2.17)$ & 0.01 \\
\hline DEV $5(n)$ & $19.13(5.87)$ & $19.90(5.37)$ & $0.77(-0.69-2.23)$ & 0.29 \\
\hline DEV $10(n)$ & $3.48(1.84)$ & $4.38(2.35)$ & $0.90(0.11-1.68)$ & 0.03 \\
\hline \multicolumn{5}{|l|}{ Sagittal plane } \\
\hline Amplitude (mm) & $7.08(1.12)$ & $7.77(1.10)$ & $0.69(0.13-1.24)$ & 0.02 \\
\hline Average speed $\left(\mathrm{mm} \cdot \mathrm{s}^{-1}\right)$ & $24.02(5.01)$ & $25.19(6.17)$ & $1.17(-0.19-2.53)$ & 0.09 \\
\hline DEV $5(n)$ & $15.98(4.53)$ & $14.96(4.39)$ & $-1.02(-2.43-0.39)$ & 0.15 \\
\hline DEV $10(n)$ & $6.50(2.47)$ & $6.58(2.53)$ & $0.08(-0.52-0.68)$ & 0.78 \\
\hline
\end{tabular}

Numbers in bold face represent P-values that are statistically significant. Mean (SD), mean difference ( $95 \%$ confidence interval) (post-exercise minus pre-exercise) and P-value (paired t-test) before (pre-exercise) and after (post-exercise) exercise, in the stabilometric variables (amplitude in $\mathrm{mm}$, average speed in $\mathrm{mm} \cdot \mathrm{s}^{-1}$, and number of movements exceeding $5 \mathrm{~mm}$ (DEV 5) and $10 \mathrm{~mm}(\mathrm{DEV} \mathrm{10})$ ) in the frontal and sagittal planes.

Table 3: Instantaneous ability to maintain balance and possible recovery after exercise, in 24 healthy subjects.

\begin{tabular}{lllll}
\hline & Measurement I Mean (SD) & Measurement 3 Mean (SD) & Mean difference (95\% CI) & P-value \\
\hline Frontal plane & & & & 0.45 \\
Amplitude $(\mathrm{mm})$ & $5.02(0.77)$ & $5.15(0.88)$ & $0.13(-0.21-0.46)$ & 0.25 \\
Average speed $\left(\mathrm{mm} \cdot \mathrm{s}^{-1}\right)$ & $24.83(6.22)$ & $24.25(5.54)$ & $-0.58(-1.60-0.44)$ & 0.09 \\
DEV 5 (n) & $20.94(5.67)$ & $19.39(5.97)$ & $-1.54(-3.32-0.23)$ & 0.24 \\
DEV I0 (n) & $4.83(2.55)$ & $4.46(2.70)$ & $-0.38(-1.02-0.27)$ & \\
Sagittal plane & & & & 0.41 \\
Amplitude (mm) & $7.81(1.44)$ & $7.52(1.34)$ & $-0.29(-1.01-0.43)$ & 0.52 \\
Average speed $\left(\mathrm{mm} \cdot \mathrm{s}^{-1}\right)$ & $25.29(6.35)$ & $25.02(6.20)$ & $-0.27(-1.13-0.59)$ & 0.90 \\
DEV 5 (n) & $14.65(4.66)$ & $14.73(5.45)$ & $0.08(-1.37-1.53)$ & 0.75 \\
DEV 10 $(\mathrm{n})$ & $6.77(2.7 \mathrm{I})$ & $6.94(3.23)$ & $0.17(-0.91-1.24)$ &
\end{tabular}

Mean (SD), mean difference (95\% confidence interval) (measurement 3 minus measurement I) and $\mathrm{P}$-value (paired t-test) for post-exercise measurements $I$ and 3 , in the stabilometric variables (amplitude in $\mathrm{mm}$, average speed in $\mathrm{mm} \cdot \mathrm{s}^{-1}$, and number of movements exceeding $5 \mathrm{~mm}$ (DEV 5 ) and $10 \mathrm{~mm}$ (DEV I0)) in the frontal and sagittal planes. 


\section{Conclusions}

No statistically significant bias between the two test sessions was found. The ICCs ranged from 0.79 to 0.95 in all stabilometric variables except one. The Bland and Altman plots with LOA revealed that small changes in an individual's performance cannot be detected. A relatively large difference in an individual's balance performance would be required to confidently state that the change is real. The stabilometric test may thus be more useful and appropriate for distinguishing between groups of subjects. The increased values of average speed and DEV 10 in the FP, and of the amplitude in the SP following cycling for a short period of time at a sub-maximal level, indicate compensatory mechanisms aimed at maintaining balance in single-limb stance, or a decreased ability to maintain balance, in young healthy subjects. Since the amplitude in the SP had poor reliability, and DEV 5 in both planes and amplitude in the FP were unaffected by exercise, these variables can be excluded in future studies. We recommend that average speed and DEV 10; the variables showing the best reliability and effects of exercise, be used in future studies. Our results indicate that measurements in the FP may be more reliable and sensitive than those in the SP.

\section{Competing interests}

None declared.

\section{Authors' contributions}

EA participated in the design of the study, participated in collecting the data, performed the statistical analysis, and drafted the manuscript. DR participated in collecting the data. EH participated in the progress and revision of the manuscript. TF participated in the design of the study, and in the progress and revision of the manuscript. All authors read and approved the final manuscript.

\section{Acknowledgements}

We would like to thank all the subjects who volunteered for this study, PerErik Isberg at the Department of Statistics, Lund University for statistical advice, Karin Bergman and Jennie Ohlsson for testing subjects for testretest reliability, the Swedish Foundation for Health Care Sciences and Allergy Research, the Swedish Rheumatism Association, "Vårdrådet" at Lund University Hospital, "Centrum för Idrottsforskning", and the Faculty of Medicine, Lund University.

\section{References}

I. Noakes TD: Physiological models to understand exercise fatigue and the adaptations that predict or enhance athletic performance Scand J Med Sci Sports 2000, I 0: I 23-I 45.

2. Shumway-Cook $A$ and Woollacott $M$ : Control of posture and balance In: Motor control. Theory and practical applications Edited by: Butler J. Baltimore, Williams \& Wilkins; 1995:I20-121.

3. Fridén T, Zätterström R, Lindstrand A and Moritz U: A stabilometric technique for evaluation of lower limb instabilities $A m \mathrm{~J}$ Sports Med 1989, I 7: I 18-122.

4. Lepers R, Bigard AX, Diard JP, Gouteyron JF and Guezennec CY: Posture control after prolonged exercise Eur J Appl Physiol 1997, 76:55-6I.
5. Nardone A, Tarantola J, Giordano A and Schieppati M: Fatigue effects on body balance Electroencephalogr Clin Neurophysiol 1997, I 05:309-320.

6. Johnston RB 3rd, Howard ME, Cawley PW and Losse GM: Effect of lower extremity muscular fatigue on motor control performance Med Sci Sports Exerc 1998, 30:1703-1707.

7. Lundin TM, Feuerbach JW and Grabiner MD: Effect of plantar flexor and dorsiflexor fatigue on unilateral postural control $J$ of Appl Biomechanics 1993, 9:191-201.

8. Yaggie JA and McGregor SJ: Effects of isokinetic ankle fatigue on the maintenance of balance and postural limits Arch Phys Med Rehabil 2002, 83:224-228.

9. Rowe A, Wright S, Nyland J, Caborn DN and Kling R: Effects of a 2hour cheerleading practice on dynamic postural stability, knee laxity, and hamstring extensibility J Orthop Sports Phys Ther 1999, 29:455-462.

10. Adlerton $A K$ and Moritz U: Does calf-muscle fatigue affect standing balance? Scand J Med Sci Sports 1996, 6:2II-2I5.

II. Rozzi S, Lephart S and Fu F: Effects of muscular fatigue on knee joint laxity and neuromuscular characteristics of male and female athletes J Athl Train 1999, 34: 106-I I4.

12. Fridén T, Erlandsson $T$, Zätterström R, Lindstrand $A$ and Moritz $U$ : Compression or distraction of the anterior cruciate injured knee. Variations in injury pattern in contact sports and downhill skiing Knee Surg Sports Traumatol Arthrosc 1995, 3: I 44- I 47.

13. Atkinson $G$ and Nevill AM: Statistical methods for assessing measurement error (reliability) in variables relevant to sports medicine Sports Med 1998, 26:217-238.

14. Birmingham TB: Test-retest reliability of lower extremity functional instability measures Clin J Sport Med 2000, 10:264-268.

15. Hoffman MA and Koceja DM: Dynamic balance testing with electrically evoked perturbation: a test of reliability Arch Phys Med Rehabil 1997, 78:290-293.

16. Ageberg E, Zätterström R and Moritz U: Stabilometry and oneleg hop test have high test-retest reliability Scand J Med Sci Sports 1998, 8:198-202.

17. Ageberg E, Zätterström R, Fridén T and Moritz U: Individual factors affecting stabilometry and one-leg hop test in $\mathbf{7 5}$ healthy subjects, aged I 5-44 years Scand J Med Sci Sports 200 I, I I :47-53.

18. Ageberg E, Zätterström R, Moritz $U$ and Fridén T: Influence of supervised and nonsupervised training on postural control after an acute anterior cruciate ligament rupture: A 3-year longitudinal prospective study J Orthop Sports Phys Ther 200I, 31:632-644.

19. Zätterström R, Fridén T, Lindstrand A and Moritz U: The effect of physiotherapy on standing balance in chronic anterior cruciate ligament insufficiency Am J Sports Med 1994, 22:53 I-536.

20. Knuttgen HG and Saltin B: Muscle metabolites and oxygen uptake in short-term submaximal exercise in man $J$ Appl Physiol 1972, 32:690-694.

21. Tegner $Y$ and Lysholm J: Rating systems in the evaluation of knee ligament injuries Clin Orthop 1985, 198:43-49.

22. Winter $D$ : Balance and posture during quite standing $\ln : A B C$ (Anatomy, Biomechanics and Control) of balance during standing and walking. Waterloo, Waterloo Biomechanics; 1995:5-2 I [http:// www.health.uottawa.ca/biomech/watbiom/book2.htm].

23. Tropp $\mathrm{H}$ and Odenrick $\mathrm{P}$ : Postural control in single-limb stance J Orthop Res 1988, 6:833-839.

24. Borg G: Psychophysical scaling with applications in physical work and the perception of exertion Scand J Work Environ Health 1990, 16:55-58.

25. Wilmore J and Costill D: Prescription of exercise for health and fitness In: Physiology of sport and exercise. Champaign, III., Human Kinetics; 1999:620-624.

26. Shrout PE and Fleiss JL: Intraclass correlations: Uses in assessing rater reliability Psychol Bull 1979, 86:420-428.

27. Bland JM and Altman DG: Statistical methods for assessing agreement between two methods of clinical measurement Lancet 1986, 1:307-310.

28. Fleiss J: Reliability of measurements In: The design and analysis of clinical experiments Edited by: Fleiss J. New York, John Wiley \& Sons; 1986:2-31.

29. MacKinnon CD and Winter DA: Control of whole body balance in the frontal plane during human walking $J$ Biomech 1993 , 26:633-644. 
30. Johansson H, Sjölander P and Sojka P: Receptors in the knee joint ligaments and their role in the biomechanics of the joint Crit Rev Biomed Eng 1991, 18:341-368.

31. Lattanzio PJ and Petrella RJ: Knee proprioception: a review of mechanisms, measurements, and implications of muscular fatigue Orthopedics 1998, 21:463-470.

32. Skinner HB, Wyatt MP, Stone ML, Hodgdon JA and Barrack RL: Exercise-related knee joint laxity Am J Sports Med 1986, 14:30-34.

33. Wojtys EM, Wylie BB and Huston LJ: The effects of muscle fatigue on neuromuscular function and anterior tibial translation in healthy knees Am J Sports Med 1996, 24:6I5-62I.

34. Skinner HB, Wyatt MP, Hodgdon JA, Conard DW and Barrack RL: Effect of fatigue on joint position sense of the knee J Orthop Res 1986, 4: I I2-118.

\section{Pre-publication history}

The pre-publication history for this paper can be accessed here:

http://www.biomedcentral.com/1471-2474/4/14/prepub

Publish with Bio Med Central and every scientist can read your work free of charge

"BioMed Central will be the most significant development for disseminating the results of biomedical research in our lifetime. "

Sir Paul Nurse, Cancer Research UK

Your research papers will be:

- available free of charge to the entire biomedical community

- peer reviewed and published immediately upon acceptance

- cited in PubMed and archived on PubMed Central

- yours - you keep the copyright

Submit your manuscript here:

http://www.biomedcentral.com/info/publishing_adv.asp
BiolMedcentral 